\title{
Acute vision loss in post-partum period as presenting symptom of HIV-associated cryptococcal meningitis-an unusual case report
}

\author{
Aniruddha More, Ravindra Kumar Garg ${ }^{*}$, Hardeep Singh Malhotra, Neeraj Kumar and Ravi Uniyal
}

\begin{abstract}
Background: Acute vision loss in the post-partum period can occur due to many reasons. Eclampsia, posterior reversible encephalopathy syndrome (PRES), pituitary apoplexy, and central serous retinopathy are some of the important causes. Cryptococcal meningitis as a cause of acute vision loss in the post-partum period has not been mentioned in literature.

Case presentation: A 25-year-old female presented to us with acute bilateral complete vision loss in the post-partum period. Her serum was tested positive for HIV antibodies. Cerebrospinal fluid (CSF) examination revealed cryptococcal meningitis. She was started on amphotericin B, antiretroviral drugs, and steroids. Though symptoms of meningitis resolved after treatment no significant improvement in vision was observed at 3 months.
\end{abstract}

Conclusions: Cryptococcal meningitis may be considered as one of the causes of acute vision loss in pregnant/ post-partum females with human immunodeficiency virus (HIV) positivity.

Keywords: Acquired immune deficiency syndrome, Human immunodeficiency virus, Meningitis, Optic nerve

\section{Background}

Approximately, 36.7 million people globally were suffering from HIV infection at end of 2015 [1]. About 17.4 million women were suffering from HIV infection worldwide in 2014 [2]. HIV infection in pregnancy has become the most common complication of pregnancy in some developing countries. In pregnancy immune function is suppressed in HIV infected as well as non-infected subjects [3]. There is a reduction in immunoglobulin, reduced complement levels and a significant decrease in cell-mediated immunity during pregnancy [3]. This leads to increased susceptibility of pregnant females to opportunistic infections like tuberculosis and cryptococcal meningitis. Cryptococcal disease is very uncommonly seen in HIV infected pregnant females and to date only three cases of HIV infection with cryptococcal meningitis have been reported during the peripartum period [4]. Symptoms of cryptococcal

\footnotetext{
* Correspondence: garg50@yahoo.com

Department of Neurology, King George Medical University, Lucknow PIN-226003, Uttar Pradesh, India
}

meningitis include fever, headache, nausea/vomiting, altered sensorium, and multiple cranial nerve palsies. Vision loss is seen in 33-47\% of patients [5]. Seven percent of HIV infected individuals suffer from cryptococcal meningitis in the course of their illness out of which only $1.9 \%$ have cryptococcal meningitis as the presenting symptom $[5,6]$. Complete bilateral vision loss as presenting symptom of HIV related cryptococcal meningitis is extremely rare [7]. Similar presentations in post-partum female, as it was in our case, are unique and high index of suspicion is necessary for accurate diagnosis.

\section{Case presentation}

A 25- year-old previously healthy pregnant female in 36th week of her gestation presented in labour to the department of Obstetrics \& Gynecology of our hospital. Before admission she was having mild to moderate headache of 10 days duration which was associated with mild fever with intermittent high grade spikes which used to subside on administration of antipyretic medications. 
Her serum tested positive, by ELISA, for antibodies towards HIV. She delivered a still-born baby vaginally. She was apparently asymptomatic for 2 days, besides fever and headache which were relieved by antipyretics and analgesics. On the 3rd day post-partum day, she woke up in the morning realizing that she was not able to see from both eyes; the loss of vision was painless and symmetrical. She was transferred to the department of Neurology unit of our hospital for further evaluation. On clinical examination, her vitals and level of consciousness were normal. Her visual acuity was significantly reduced and she could only perceive light in both eyes. Her pupils were completely dilated and not reacting to light. Fundus examination revealed bilateral edematous optic discs suggestive of papillitis. Other cranial nerves were normal on examination. Motor and sensory system examination were normal. Plantar reflex was bilaterally flexor. She had neck stiffness and Kerning's sign was positive. Urgently a CT scan of her head was done which showed no significant abnormality and then her CSF examination was done based on her clinical signs. Her CSF opening pressure was mildly elevated $(200 \mathrm{cms}$ of $\mathrm{H}_{2} \mathrm{O}$ ). CSF examination showed mild pleocytosis (35 cells $/ \mathrm{mm}^{3}$ ) with lymphocytic predominance, mildly elevated proteins $(76.5 \mathrm{mg} \%$ ) and low sugars $(32.7 \mathrm{mg} \%$ with corresponding blood glucose of $117 \mathrm{mg} \%)$. Her CSF was tested positive for Cryptococcus by India ink staining (Fig. 1). The CSF showed a titre of 1:100 for cryptococcal antigen by latex agglutination method. Since she was diagnosed with cryptococcal meningitis she was categorized as having stage 4 disease according to WHO clinical staging for HIV/AIDS. All other hematological and biochemical parameters were within normal limits. Her CD4 counts were done which turned out to be 166 cells $/ \mathrm{mm}^{3}$. The plasma HIV-RNA levels were not

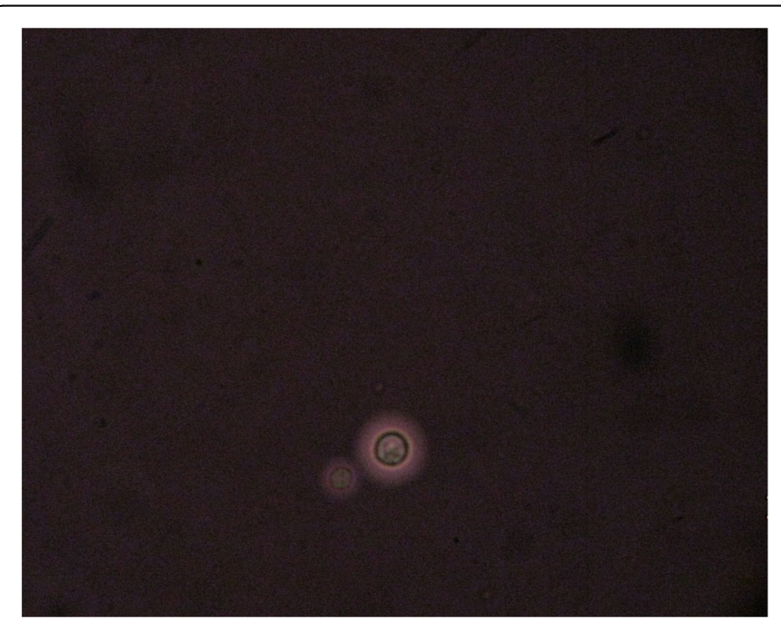

Fig. 1 India ink preparation showing capsules of Cryptococcus neoformans performed in this case. As per National AIDS Control Guidelines of India prior HIV-RNA levels assessment, before starting antiretroviral drugs, is not mandatory. Her MRI was planned to evaluate the cause of her blindness which showed signal intensity changes in bilateral optic nerve and (cryptococcoma/cryptococcal) infiltration in bilateral ganglio-capsular region (soap-bubble appearance) (Fig. 2). She was initiated on amphotericin-B $0.7 \mathrm{mg} / \mathrm{kg} /$ day IV once daily (slow infusion) and intravenous methylprednisolone $1 \mathrm{gm}$ IV once daily (for 5 days), and an antiretroviral regimen consisting of zidovudine (300 mg once daily), lamivudine (150 mg once daily), and nevirapine (200 mg once daily) was planned. She received amphotericin B for 21 days after which she was started on tablet fluconazole $400 \mathrm{mg}$ per day which was continued for 8 weeks. Antiretroviral medications were started after completion of intravenous antifungal medications. Her headache improved with treatment and she became afebrile. Repeat CSF examination was negative for Cryptococci by India ink staining. Though she showed significant improvement in meningitic symptoms, her vision did not show any significant improvement even at end of 3 months of her illness.

\section{Discussion}

Acute vision loss in the post-partum period is reported due to severe preeclampsia/eclampsia (in which vision loss could be due to exudative retinal detachment, hypertensive retinopathy and cortical blindness) [8], PRES which can cause reversible acute vision loss [9], pituitary apoplexy [10], posterior ischemic optic neuropathy [11], anterior ischemic optic neuropathy [12], cortical venous sinus thrombosis [13], and central serous retinopathy [14]. Cryptococcal meningitis as a cause of acute vision loss in the post-partum period has not yet been reported in literature.

Vision loss in HIV infected individuals can be due to infectious and non-infectious causes [15-17]. HIV retinopathy is the most common non-infectious ocular complication. Amongst infectious causes cytomegalovirus retinitis is considered as the most common ocular infection. Neuro-ophthalmic lesions affected $6 \%$ of individuals of acquired immunodeficiency states of which most common cause was cryptococcal meningitis. Approximately 25 to $50 \%$ patients with cryptococcal meningitis demonstrate a neuro-ophthalmic complication. In a cross-sectional analysis looking at the ophthalmic complications in the pre-HAART (Highly Active AntiRetroviral Therapy) and HAART period, it has been suggested that despite of an advancement in terms of treatment the difference between the two treatment protocols has not been significant (pre-HAART $(41.67 \%)$ versus HAART (38 \%). Of significance was the fact that the odds of development of ophthalmic 


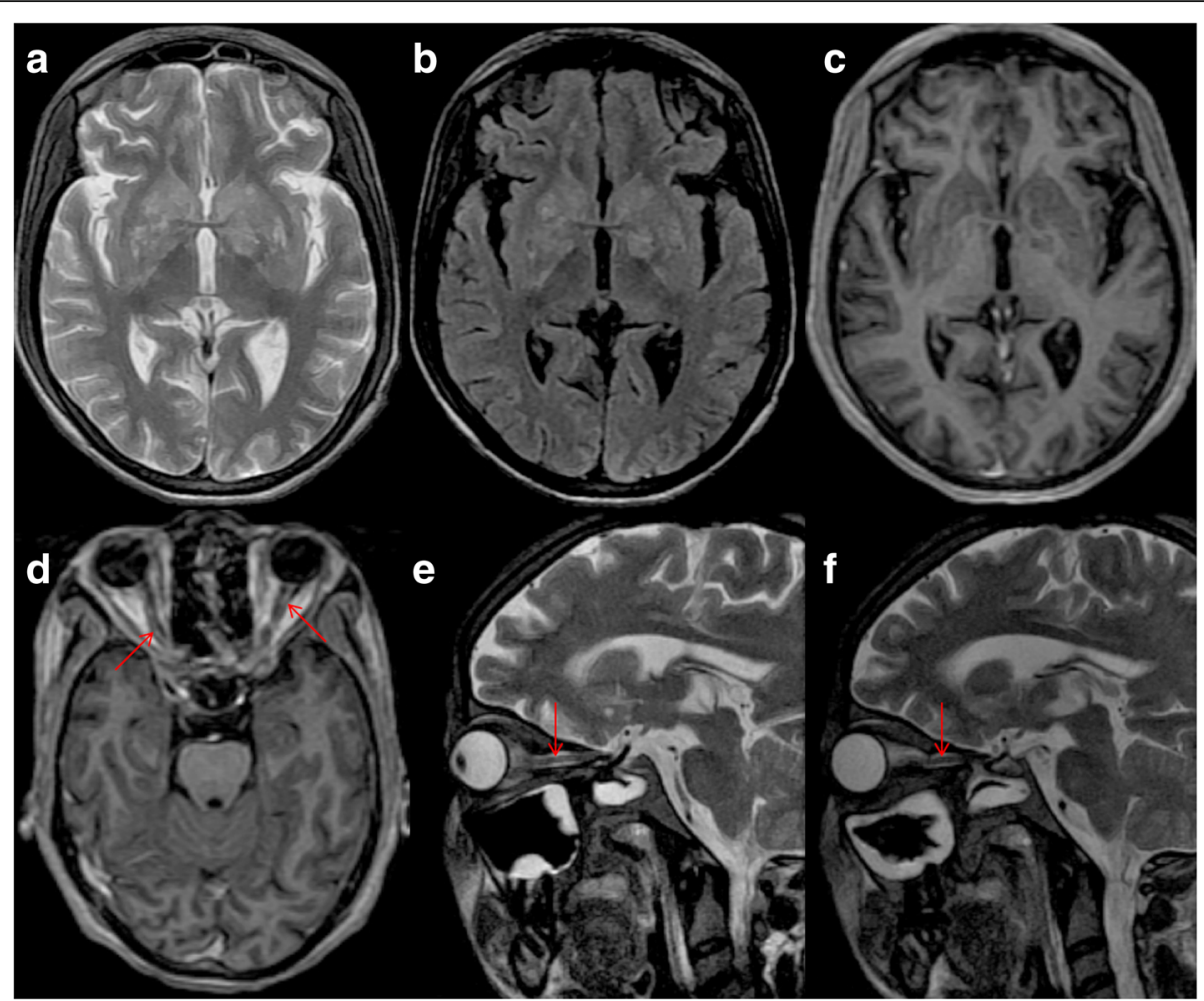

Fig. $2 \mathrm{MRI}$ of the brain depicts hyperintense signal intensity changes in the basal ganglia on axial T2-weighted (a) and FLAIR (b) sequences. There is no suggestion of contrast uptake in the basal ganglia (c) while both optic nerves demonstrate enhancement (d) on SPGR-GAD sequence. T2-weighted para-sagittal orbital sections show hyperintensity in the right (e) and the left (f) optic nerves (arrows)

complications with a CD4 count of $>200$ cells $/ \mu \mathrm{L}$ were significantly higher (4.87) during the HAART period [17]. Since most patients with ophthalmic complications have been noted to present in WHO stage 3 and 4 , it has been recommended that regular ophthalmic assessments are done in patients with HIV positivity.

Cryptococcal meningitis is one of potentially fatal opportunistic infection seen in HIV infected individuals. The causative agent is Cryptococcus neoformans, an encapsulated fungus commonly isolated from pigeon droppings. Humans are infected by inhalation of organism [18]. Human to human transmission is yet to be documented [19]. Signs and symptoms of cryptococcal meningitis include headache (80-92\%), meningeal signs (50-80\%), nausea/ vomiting (40-80\%), fever (36-67\%), cranial nerve palsies (28-60\%), vision disturbances (33-47\%), confusion/ somnolence (33-40\%), ataxia/gait disturbance (26$40 \%$ ), papilledema (28-33\%), seizures (13-15\%) [5].

Vision loss in cryptococcal meningitis can be rapid ( $<3$ days) occurring as rapidly as $12 \mathrm{~h}$ or can occur slowly ( $>3$ days) over weeks to months [20]. Possible mechanisms of rapid visual loss include direct invasion of optic nerve by Cryptococcus, optic neuritis, and optochiasmatic arachnoiditis while a possible mechanism for slow vision loss has been attributed to raised intracranial pressure [20]. Factors predicting vision loss are presence of papilledema, high CSF opening pressure, and a positive India ink preparation. In cases with acute vision loss despite of giving antifungals and steroids no substantial improvement in vision is expected and these cases tend to have a poor prognosis for visual recovery. In cases with slow visual loss therapeutic measures to reduce intracranial pressure like shunting or optic nerve sheath fenestration have been shown to halt vision loss and shown improvement in some cases [20].

Vision loss in our patient was most probably due to infiltration of optic nerve by Cryptococcus causing optic neuritis and acute vision loss. This was supported by fact that her MRI showed enhancement of both optic nerves and presence of papillitis on ophthalmoscopy with cryptococcal infiltration in both ganglio-capsular regions. This also explains her poor recovery of vision despite of receiving steroids as noted in previous studies (Table 1). The general belief that pregnancy is a state of immune suppression may not hold true in all patients. Pregnancy, indeed, is a state of an altered immune status which may respond to different stimuli variably. Thus, in the background of pregnancy and a HIV positive state, this rare manifestation of Cryptococcus appears to have evolved [21]. 
Table 1 A review of published cases of vision loss in Cryptococcal meningitis (Cases, reported after year 2000 and those who had a MRI done, were included)

\begin{tabular}{|c|c|c|c|c|c|}
\hline Reference & HIV status & Summary of case & MRI & Suggested cause of vision loss & Outcome \\
\hline \multirow[t]{2}{*}{ Ng et al. [22] } & Positive & $\begin{array}{l}\text { A 39-year-old Chinese man presented with } \\
\text { bitemporal headache, giddiness and vomiting } \\
\text { over a period of } 2 \text { days. There was no } \\
\text { Cryptococcus detected by Indian ink } \\
\text { examination of the CSF but CSF culture grew } \\
\text { Cryptococcus neoformans. The patient was } \\
\text { treated with amphotericin, and then to } \\
\text { fluconazole. }\end{array}$ & Normal & increased intracranial pressure & $\begin{array}{l}\text { irreversible blindness in } \\
\text { both eyes }\end{array}$ \\
\hline & Positive & $\begin{array}{l}\text { A 36-year-old Chinese man presented with } \\
\text { subacute onset of severe headache and } \\
\text { confusional state. CSF microscopy with Indian } \\
\text { ink examination showed Cryptococcus. Eight } \\
\text { days after starting IV amphotericin, he } \\
\text { complained of bilateral blurring of vision and } \\
\text { had a seizure. A repeat lumbar puncture } \\
\text { showed raised opening CSF pressure of more } \\
\text { than } 40 \mathrm{~cm} \text { and } 20 \mathrm{~mL} \text { of CSF was withdrawn. } \\
\text { During follow up, concentric diminution of } \\
\text { visual field in both eyes was recorded. A } \\
\text { lumbo-peritoneal shunt was done. }\end{array}$ & CT was normal & Increased intracranial pressure & Normal vision \\
\hline Mohan et al. [23] & Positive & $\begin{array}{l}\text { A } 41 \text {-year-old male with a history of cryptococcal } \\
\text { meningitis admitted with severe headache. On the } \\
6 \text { th day, He had complete loss of hearing, vision } \\
\text { loss as well as bilateral facial palsy and bilateral } \\
\text { sixth nerve palsy. Bilateral papilledema was seen. } \\
\text { CSF opening pressure was } 460 \mathrm{~mm} \mathrm{H} 2 \mathrm{O} \text {. } \\
\text { Amphotericin and Flucytosine were given. } \\
\text { Repeated lumbar punctures were done but } \\
\text { pressure remained over } 500 \mathrm{~mm} \mathrm{H} 2 \mathrm{O} \text {. Ommaya } \\
\text { reservoir placed. There was dramatic clinical } \\
\text { improvement of the patient. }\end{array}$ & Hydrocephalus & Increased intracranial pressure & Regained his vision partially \\
\hline Hong et al. [7] & Positive & $\begin{array}{l}\text { A 58-year-old man presented with acute vision } \\
\text { loss. Patient had normal CSF opening pressure } \\
\text { and fundus. He received antiretroviral and } \\
\text { antifungal agents. }\end{array}$ & Normal & $\begin{array}{l}\text { Possibly, direct fungal infiltration } \\
\text { of the optic nerve, optic chiasm, } \\
\text { or optic tracts }\end{array}$ & Vision improved \\
\hline Milman et al. [24] & Positive & $\begin{array}{l}25 \text {-year-old patient developed headaches, } \\
\text { seizures, altered mental status, and visual loss. } \\
\text { Lumbar puncture showed markedly increased }\end{array}$ & $\begin{array}{l}\text { leptomeningeal and optic } \\
\text { nerve enhancement } \\
\text { without hydrocephalus }\end{array}$ & increased intracranial pressure & $\begin{array}{l}\text { Improved with bilateral optic } \\
\text { nerve sheath fenestration. }\end{array}$ \\
\hline
\end{tabular}


Table 1 A review of published cases of vision loss in Cryptococcal meningitis (Cases, reported after year 2000 and those who had a MRI done, were included) (Continued)

Duggan and Walls [27] Positive $\quad$ A 39-year-old man with AIDS presented with

CSF showed C neoformans. Amphotericin and

flucytosine were started. On day 2, the patient had

several episodes of complete loss of vision

bilaterally. Drainage of CSF to decrease ICP resulted

in the immediate return of vision. External

ventricular drain was placed and later optic nerve sheath fenestration.

Positive A 39-year-old African female with AIDS presented with headache, neck pain, and altered mental status of 3 days. CSF showed $C$ neoformans. On hospital day 2, the patient complained of sudden complete loss of vision bilaterally. Retinal

microvasculopathy was noted.

Espino Barros Palau et al. [28] Out of three A 46-year-old male had bilateral optic atrophy. He cases one was had been well until 3 months prior when he HIV positive experienced vision loss, headache, nausea, and fever.

A 43-year-old female presented with 3 weeks of headache, horizontal diplopia, and bilateral vision loss. Patient had renal transplantation requiring immunosuppression in 2005. CSF opening pressure was markedly elevated. Amphotericin B and flucytosine were initiated.

A 35-year-old male presented with 1 month of bilateral progressive vision loss. Ophthalmoscopy showed peripapillary subretinal fluid extending into the macula bilaterally. Both optic discs had edema. CSF opening pressure was elevated. Amphotericin B and flucytosine were started.

CT scan of the brain was normal high intracranial pressure His vision was improved to $6 / 6$ in both eyes with (6/6 in bot field.

retrobulbar neuritis

optic nerve edema or neuritis

Normal

Normal

Diffuse leptomeningeal enhancement and punctate areas of

enhancement in the pons and basal ganglia.

Multiple T2-hyperintense lesions throughout the cerebral hemispheres,

brainstem, and cerebellum as well as with

leptomeningeal enhancement.
IRIS leading to optic nerve neuritis following

anti-retroviral therapy

high intracranial pressure

At 3 months, vision was normal After starting ART and IV methyl-prednisolone

permanent vision loss

Retinal microvasculopathy

Patient died

Intracranial hypertension

serial lumbar drain 
Table 1 A review of published cases of vision loss in Cryptococcal meningitis (Cases, reported after year 2000 and those who had a MRI done, were included) (Continued)

\begin{tabular}{|c|c|c|c|c|c|}
\hline Portelinha et al. [29] & Negative & $\begin{array}{l}\text { A 52-year-old woman with headaches, vomiting } \\
\text { and fatigue for } 3 \text { weeks. She was diagnosed with } \\
\text { cryptococcal meningitis and treated with antifungal } \\
\text { therapy. She also had decreased vision in the left } \\
\text { eye, bilateral sixth nerve palsy and papilloedema. A } \\
\text { ventriculo-peritoneal shunt was placed and } \\
\text { methylprednisolone was started. }\end{array}$ & $\begin{array}{l}\text { Signs of intracranial hypertension } \\
\text { as well as multiple parenchymal } \\
\text { lesions and optic nerve sheath } \\
\text { enhancement. }\end{array}$ & $\begin{array}{l}\text { high intracranial pressure and } \\
\text { optic nerve fungal infiltration }\end{array}$ & $\begin{array}{l}\text { In spite of the control of } \\
\text { intracranial pressure there } \\
\text { was a decrease in vision in } \\
\text { the right eye and } \\
\text { deterioration of visual fields. }\end{array}$ \\
\hline Ghatalia et al. [30] & Positive & $\begin{array}{l}\text { A } 34 \text { year old man of vision loss in a patient with } \\
\text { Cryptococcal meningitis and normal ICP. }\end{array}$ & $\begin{array}{l}\text { Abnormal circumferential } \\
\text { enhancement within the } \\
\text { bilateral optic nerve sheaths. }\end{array}$ & $\begin{array}{l}\text { IRIS leading to optic nerve } \\
\text { neuritis }\end{array}$ & $\begin{array}{l}\text { Vision improved with } \\
\text { corticosteroids }\end{array}$ \\
\hline Merkler et al. [31] & Negative & $\begin{array}{l}\text { A 38-year-old woman presented with bilateral vision } \\
\text { loss. Empiric steroids resulted in improvement in } \\
\text { visual acuity, while tapering steroids, she had visual } \\
\text { loss again. }\end{array}$ & $\begin{array}{l}\text { Multiple areas of ill-defined } \\
\text { enhancement in the optic } \\
\text { chiasm and tracts. }\end{array}$ & $\begin{array}{l}\text { Invasion of the optic apparatus } \\
\text { by Cryptococcus neoformans }\end{array}$ & One year later, symptom free. \\
\hline
\end{tabular}




\section{Conclusions}

Cryptococcal meningitis may be considered as one of causes of acute vision loss in HIV-infected pregnant females with suggestive symptoms; needless to say that a high index of suspicion should be kept to diagnose the condition. Though prognosis of visual recovery is poor in cases of acute vision loss, early therapeutic measures to relieve intracranial pressure may potentially halt the progression while some recovery may be observed in cases with slowly progressive vision loss.

\section{Abbreviations}

AIDS: Acquired immune deficiency syndrome; ART: Antiretroviral therapy; CSF: Cerebrospinal fluid; CT: Computed tomography; HAART: Highly Active Anti-Retroviral Therapy; HIV: Human immunodeficiency virus; ICP: Intracranial pressure; IRIS: Immune Reconstitution Inflammatory Syndrome;

IV: Intravenous; MRI: Magnetic Resonance Imaging; PRES: Posterior reversible encephalopathy syndrome

\section{Acknowledgement}

None.

\section{Funding}

Not applicable.

\section{Availability of data and materials}

All the data supporting our findings is contained within the manuscript.

\section{Authors' contributions}

AM Case evaluation, contributing in work up of the patient and writing the manuscript. RKG Case evaluation, contributing in work up of the patient and writing the manuscript. HSM Review of literature and writing the manuscript. NK Review of literature and writing the manuscript. RU Case evaluation, contributing in work up of the patient and writing the manuscript. All authors read and approved the final manuscript.

\section{Competing interests}

On behalf of all authors, the corresponding author states that there is no conflict of interest.

\section{Consent for publication}

Written informed consent was obtained from the patient/legal guardian.

\section{Ethics approval and consent to participate}

Not applicable.

Received: 7 July 2016 Accepted: 12 October 2016

\section{Published online: 19 October 2016}

\section{References}

1. Unaids.org. Fact sheet 2016 | UNAIDS [Internet]; 2016. Available from: http:// www.unaids.org/en/resources/fact-sheet. Cited 19 Jun 2016.

2. World Health Organization. Number of women living with HIV [Internet]; 2016. Available from: http://www.who.int/gho/hiv/epidemic_status/cases_ adults_women_children/en/. Cited 19 Jun 2016.

3. Minkoff $H$. Pregnancy and HIV infection. In: Minkoff $H$, DeHovitz JA, Duerr A editors. HIV infection in women. New York: Raven; 1995. p. 173-88.

4. Nayak S, Talwani R, Gilliam B, Taylor G, Ghosh M. Cryptococcal Meningitis in an HIV-Positive Pregnant Woman. J Int Assoc Physicians AIDS Care (Chic). 2011:10:79-82

5. Giberson TP, Kalyan-Raman K. Cryptococcal meningitis: initial presentation of acquired immunodeficiency syndrome. Ann Emerg Med. 1987;16:802-4

6. Johnston SR, Corbett EL, Foster O, Ash S, Cohen J. Raised intracranial pressure and visual complications in AIDS patients with cryptococcal meningitis. J Infect. 1992:24:185-9.

7. Hong YJ, Jung S, Kim JY, Kwon SB, Song KB, Hwang SH, Min YK, Kwon KH, Lee BC. Complete Binocular Blindness as the First Manifestation of HIV-Related Cryptococcal Meningitis. J Clin Neurol. 2007;3:212-4.
8. Waziri-Erameh MJ, Omoti AE, Edema OT. Bilateral total loss of vision following eclampsia — a case report. Afr J Reprod Health. 2003;7:106-8.

9. Lee VH, Wijdicks EF, Manno EM, Rabinstein AA. Clinical spectrum of reversible posterior leukoencephalopathy syndrome. Arch Neurol. 2008;65:205-10.

10. Boellis A, di Napoli A, Romano A, Bozzao A. Pituitary apoplexy: an update on clinical and imaging features. Insights Imaging. 2014;5:753-62.

11. Rishi K, Puri M. Posterior Ischaemic Optic Neuropathy Following Vaginal Delivery. Webmed Central Ophthalmol. 2012;3:WMC003307. doi:10.9754/journal.wmc.2012.003307.

12. Giridhar P, Freedman K. Nonarteritic Anterior Ischemic Optic Neuropathy in a 35-Year-Old Postpartum Woman With Recent Preeclampsia. JAMA Ophthalmol. 2013;131:542-4

13. Femi OL, Mohammed H, Musa BM, Ibrahim DA, Gwaram BA, Dutse Al. Puerperal superior sagittal sinus thrombosis and pulmonary embolism: A case report and review of literature. J Basic Clin Reprod Sci. 2014:3:64-7. Downloaded from: http://www.jbcrs.org/article.asp?issn=2278-960X;year= 2014; volume $=3$;issue $=1 ;$ spage $=64$; epage $=67$; aulast=Femi. Assessed on 29 Jun 2016.

14. Gass JD. Central serous chorioretinopathy and white subretinal exudation during pregnancy. Arch Ophthalmol. 1991;109:677-81.

15. Jabs DA. Ocular manifestations of HIV infection. Trans Am Ophthalmol Soc. 1995:93:623-83.

16. Martin-Odoom A, Bonney EY, Opoku DK. Ocular complications in HIV positive patients on antiretroviral therapy in Ghana. BMC Ophthalmol. 2016:16:134.

17. Agarwal A, Singh R, Sharma A, Gupta V, Dogra MR. Ocular Manifestations in Patients with Human Immunodeficiency Virus Infection in the Pre-HAART Versus the HAART Era in the North Indian Population. Ocul Immunol Inflamm. 2016;24: 1-9. [Epub ahead of print] http://dx.doi.org/10.3109/09273948.2015.1133837.

18. Sabetta JR, Andriole VT. Cryptococcal infections of the central nervous system. Med Clin North Am. 1985;69:333-44.

19. Braude Al, Davis CE, Fierer J, editors. Infectious Diseases and Medical Microbiology. Philadelphia: WB Saunders Company; 1986. p. 564-70.

20. Rex JH, Larsen RA, Dismukes WE, Cloud GA, Bennett JE. Catastrophic visual loss due to Cryptococcus neoformans meningitis. Medicine (Baltimore). 1993:72:207-24

21. Mor G, Cardenas I. The immune system in pregnancy: a unique complexity. Am J Reprod Immunol. 2010:63:425-33.

22. $\mathrm{Ng}$ CW, Lam MS, Paton NI. Cryptococcal meningitis resulting in irreversible visual impairment in AIDS patients_-a report of two cases. Singap Med J. 2000;41:80-2.

23. Mohan S, Ahmed SI, Alao OA, Schliep TC. A case of AIDS associated cryptococcal meningitis with multiple cranial nerve neuropathies. Clin Neurol Neurosurg. 2006;108:610-3.

24. Milman T, Mirani N, Turbin RE. Optic nerve sheath fenestration in cryptococcal meningitis. Clin Ophthalmol. 2008;2:637-9.

25. Muslikhan Y, Hitam WH, Ishak SR, Mohtar I, Takaran J. Cryptococcus meningitis in an immunocompetent teenage boy presented early with diplopia. Int J Ophthalmol. 2010;3:92-4.

26. De Socio GV, Bernini L, Menduno P, Pitzurra L, Leone F, Baldelli F. Monolateral visual loss due to cryptococcal meningitis. J Int Assoc Physicians AIDS Care (Chic). 2011;10:76-8

27. Duggan J, Walls HM. Ocular complications of cryptococcal meningitis in patients with HIV: report of two cases and review of the literature. J Int Assoc Physicians AIDS Care (Chic). 2012;11:283-8.

28. Espino Barros Palau A, Morgan ML, Foroozan R, Lee AG. Neuro-ophthalmic presentations and treatment of Cryptococcal meningitis-related increased intracranial pressure. Can J Ophthalmol. 2014;49(5):473-7. doi:10.1016/j.jcjo. 2014.06.012

29. Portelinha J, Passarinho MP, Almeida AC, Costa JM. Bilateral optic neuropathy associated with cryptococcal meningitis in an immunocompetent patient. BMJ Case Rep. 2014;2014. doi:10.1136/bcr-2013-203451

30. Ghatalia PA, Vick A, Vattoth S, Roberson GH, Pappas PG. Reversible blindness in cryptococcal meningitis with normal intracranial pressure: case report and review of the literature. Clin Infect Dis. 2014:59:310-3.

31. Merkler AE, Gaines N, Baradaran H, Schuetz AN, Lavi E, Simpson SA, Dinkin MJ. Direct Invasion of the Optic Nerves, Chiasm, and Tracts by Cryptococcus neoformans in an Immunocompetent Host. Neurohospitalist. 2015;5:217-22. 